\title{
Compreensão dos estudantes do ensino fundamental sobre seleção de uma amostra representativa
}

Tâmara Marques da Silva Gomes

Gilda Lisbôa Guimarães

\section{Resumo}

Esse estudo tem como objetivo identificar a compreensão de estudantes do $5^{\circ}$ e $9^{\circ}$ ano do Ensino Fundamental na elaboração e análise de critérios para escolha de uma amostra representativa. Foram realizadas, individualmente, entrevistas semi-estruturadas com 40 alunos (20 de cada ano), os quais foram igualmente questionados sobre diferentes habilidades relacionadas ao processo de seleção, tamanho e representatividade de uma amostra. Os estudantes apresentaram dificuldades em perceber as relações entre tamanho, variabilidade e representatividade da amostra. Contudo, os alunos que responderam de forma adequada evidenciam a possibilidade de estudantes, desde o $5^{\circ}$ ano do Ensino Fundamental, serem capazes de desenvolver habilidades necessárias para elencar critérios para a validade de uma amostra.

Palavras-chave: Amostra, Representatividade, Variabilidade. 


\title{
Understanding of elementary school students of selecting a representative sample
}

\author{
Tâmara Marques da Silva Gomes \\ Gilda Lisbôa Guimarães
}

\section{Abstract}

This study aims to identify the understanding presented by students of the $5^{\text {th }}(9-10$ years $)$ and $9^{\text {th }}(13-14$ years $)$ grade of elementary school in the elaboration and analysis of criteria for choosing a representative sample. Were done, individually, semi-structured interviews with 40 students (20 each year), which were also questioned about the different skills related selection process, size and representativeness of a sample. It was observed that students have difficulty understanding the relations between size, variability and representativeness of the sample. However, the most appropriate responses give evidence that if instigated, students from the $5^{\text {th }}$ grade are able to develop skills needed to list criteria for the selection of a valid sample.

Keywords: Sample, Representativeness, Variability. 


\section{Introdução}

A estatística e seu ensino têm sido cada vez mais valorizada, uma vez que a mesma permite analisar informações de diferentes naturezas. O conhecimento estatístico é essencial para uma reflexão crítica e para uma cidadania participativa (CARVALHO E SOLOMON, 2012).

Acreditamos que o ensino de estatística deve ter a pesquisa como seu eixo estruturador, tanto para os alunos, como para professores de todos os níveis de ensino. A pesquisa é uma forma de apropriação de saberes de forma autônoma, permitindo uma prática reflexiva de mundo.

A pesquisa pode abordar diversos campos do saber, contribuindo efetivamente para a uma aprendizagem interdisciplinar. Além disso, ela favorece a interação entre os alunos, desses com as práticas sociais e com a natureza, incentiva a linguagem oral, propicia o contato com representações diversas que resumem informações e favorece a observação e o desenvolvimento do raciocínio.

Diante destas exigências, percebe-se a importância de pensar em estratégias para o desenvolvimento da análise de dados utilizando-se de questões que envolvam a coleta, organização e apresentação de dados, utilizando métodos e ferramentas apropriados para elaboração e avaliação de inferências e predições, levando em conta a problematização por parte dos próprios estudantes.

Para a construção de tal raciocínio estatístico, a utilização de situações que envolvam conceitos relacionados à amostragem é uma possibilidade para o ensino de Estatística, visto que o processo de seleção de uma amostra demanda habilidades necessárias a crítica e análise de dados (GOMES, 2013). Nesse sentido, este artigo traz as compreensões apresentadas por estudantes do $5^{\circ}$ e $9^{\circ}$ ano do Ensino Fundamental na elaboração e análise de critérios para escolha de uma amostra representativa.

\section{Educação Estatística}

O ensino da Estatística deve proporcionar ao indivíduo o entendimento dos fenômenos sociais e com a natureza a partir da interpretação de dados e informações, levando os mesmos a serem letrados estatisticamente. Gal (2002) define o letramento estatístico como:

a) competência da pessoa para interpretar e avaliar criticamente a informação estatística, os argumentos relacionados aos dados ou aos fenômenos estocásticos, que podem se apresentar em qualquer contexto e, quando relevante, b) competência da pessoa para discutir ou comunicar suas reações para tais informações estatísticas, tais como seus entendimentos do significado da informação, suas opiniões sobre as implicações desta 
informação ou suas considerações acerca da aceitação das conclusões fornecidas (GAL, 2002, p. 2-3).

Uma pessoa é considerada letrada estatisticamente, segundo Gal (2002), quando apresenta algumas capacidades: percebe a necessidade de trabalhar com dados (compreendendo que os dados não são unicamente números, mas números inseridos num determinado contexto), conhecendo sua proveniência e a forma de produzi-los; está familiarizado com os termos e ideias básicas da Estatística Descritiva; reconhece os termos e conceitos básicos relacionados às apresentações gráficas e tabulares; compreende noções básicas de probabilidade; entende o mecanismo do processo inferencial ao tomar decisões estatísticas.

Para Garfield (2003) ao construírem conhecimento estatístico os estudantes são capazes de questionar a validade de representações e interpretações de dados e de generalizações realizadas a partir de um único estudo e/ou de amostras pequenas.

O ensino da Probabilidade e da Estatística contribui para a formação dos estudantes, preparando-os para a realidade, pois favorecem o desenvolvimento e a elaboração de questões de uma investigação, de conjecturas e hipóteses, etapas essas que são necessárias à resolução de problemas.

Para que os cidadãos possam tomar decisões baseados em dados e informações é necessário que estes possuam habilidades críticas relacionadas à Estatística. A capacidade de interpretar e avaliar criticamente uma informação estatística é fundamental para a tomada de decisão.

Diante destas exigências, observa-se a necessidade do desenvolvimento da análise de dados a partir de questões que possam ser tratadas por meio da coleta, organização e apresentação de dados, utilizando métodos e ferramentas adequados para construção e avaliação de inferências e predições, destacando-se a importância da problematização por parte dos próprios estudantes.

É perceptível a necessidade de conhecimentos de Estatística para nossa atuação na sociedade, mais do que compreender conceitos, técnicas e representações isolados, a aprendizagem da estatística requer a apropriação do processo de investigação estatística.

Uma investigação estatística, ou seja, uma pesquisa é um processo sistemático que busca gerar conhecimentos novos ou discutir conhecimentos antigos de forma a corroborálos ou refutá-los. A pesquisa deve fazer parte da vida escolar em todos os níveis de ensino. Considera-se como fundamental na atitude investigativa a preocupação em observar, formular questões, elaborar hipóteses, escolher instrumentos adequados para a resolução de problemas e a tomada de decisão. A pesquisa estatística assume métodos cientificamente testados e estruturados, ou seja, um processo sistemático de análise quantitativa de dados ISSN 2526-2882 
qualitativos ou quantitativos na busca de gerar novos conhecimentos, ou discutir conhecimentos antigos (GUIMARÃES e GITIRANA, 2013).

Diante destas exigências, percebe-se a necessidade de pensar em estratégias para o desenvolvimento da análise de dados a partir de questões que envolvam a coleta, organização e apresentação de dados, utilizando métodos e ferramentas apropriados para elaboração e avaliação de inferências e predições, levando em conta a problematização por parte dos próprios estudantes.

Para que isso ocorra é fundamental que o ensino de Estatística esteja baseado em problemas significativos para os alunos, inserindo-os no processo exploratório de investigação, visando desenvolver a capacidade de interpretação, reflexão e aplicação de conceitos matemáticos no cotidiano, tornando-os mais próximos do aprendiz.

Conceitos relacionados à amostragem são essenciais para o desenvolvimento das habilidades anteriormente mencionadas e para a realização de inferências, sendo necessário o trabalho dessa área da Estatística para a formação do educando e letramento estatístico (BUSSAB e MORETTIN, 2002).

\section{O conceito de amostragem na Educação Básica}

Para Ben-Zvi, Makar, Bakker e Aridor (2011) o conceito de amostra é central para a Estatística, entretanto tem recebido pouca atenção se comparado a conceitos como média, variabilidade e inferências informais ${ }^{6}$.

Bussab e Morettin (2002) consideram que a utilização de informações de uma amostra para conclusão de algo referente ao todo faz parte do cotidiano das pessoas. Por exemplo, ao provar uma fruta na feira, decidimos se iremos comprar ou não mais daquela fruta; um cozinheiro prova um pouco da sopa para ver se está "no ponto" ou quando, no supermercado, recebemos amostras de um novo produto para conhecê-lo e decidirmos se iremos comprar. Apesar de não percebermos, essas decisões que tomamos no nosso dia a dia são baseadas em procedimentos amostrais.

Segundo Dancey e Reidy (2006) ao produzir e analisar dados estatísticos deve-se levar em consideração as diferenças e relações entre amostras e populações. Quando se fala em população, considera-se um grupo distinto de seres vivos ou até mesmo objetos inanimados. A amostra é uma seleção de elementos da população.

É fundamental que haja um planejamento para a extração de uma amostra a partir de um procedimento de amostragem mais adequado à situação de pesquisa, visto que o

${ }^{6}$ Utilizamos o termo inferências informais, pois para realização de inferências estatísticas demanda-se conhecimento mais aprofundado das técnicas de amostragem, o que não é objetivo da Educação Básica. 
propósito desta é fornecer dados que possibilitem a descrição mais adequada possível dos parâmetros do universo da população de interesse. Assim, para que a amostra seja considerada representativa, é essencial que as características desta se assemelhem ao máximo à população estudada.

Para selecionar uma amostra representativa, é preciso levar em consideração a variável de interesse e sua variabilidade, o tamanho da amostra, a técnica de amostragem mais adequada ao objetivo de pesquisa, as limitações de tempo e orçamento, entre outros fatores. Esses aspectos colaboram para a representatividade amostral.

Em suma, ao realizar-se um estudo, deve-se conhecer a população analisada a fim de selecionar adequadamente a amostra, evitando que os resultados alcançados pela amostra possuam um viés de seleção, ou seja, que a amostra seja tendenciosa7, pois o objetivo primordial da amostragem é a representatividade ${ }^{8}$ da população.

É a partir da amostra que reunimos algumas informações sobre a população. Logo, segundo Rubin, Bruce e Tenney (1990), o cuidado na seleção da amostra é de suma importância quando utilizamos a estatística inferencial, já que esta busca analisar e interpretar os dados obtidos a partir da Estatística Descritiva, possibilitando conclusões e inferências informais sobre determinada população.

A característica fundamental que determina a força de uma generalização estatística é a representatividade da amostra. Em outras palavras, em que medida as características da população que nos preocupam estão refletidas exatamente nas características da amostra (INNABI, 2006).

Em suas pesquisas, Innabi (2006) elenca dois critérios que devem ser considerados para que a amostra seja representativa: a amostra é grande o suficiente; a amostra é bastante variada, ou seja, apresenta as características da população de interesse. Em alguns casos, uma amostra pequena pode apoiar uma generalização forte, em outros, é necessária uma amostra maior. A verdadeira questão é se a amostra é grande o suficiente para capturar, ou representar, a variedade presente na população. Perceber essa relação é uma das dificuldades enfrentadas pelos estudantes.

Em relação à variabilidade, Watson e Kelly (2002), realizaram um estudo sobre a compreensão de estudantes da grade $3^{9}$, entre 8 e 9 anos, acerca da variabilidade estatística. Realizaram pré e pós-testes associados a 10 aulas que trataram de conteúdos curriculares envolvendo chance e dados com ênfase na variação. Inicialmente os estudantes não levaram

7 Considera-se amostra tendenciosa ou enviesada aquela que é viciada no que se refere a uma ou mais características que a impedem de ser considerada representativa da população que foi extraída.

${ }^{8}$ Uma amostra para ser boa tem que ser representativa, ou seja, deve conter na mesma proporção tudo o que a população possui.

9 No Brasil equivale a estudantes do $3^{\circ}$ e $4^{\circ}$ anos ( 8 e 9 anos). ISSN 2526-2882

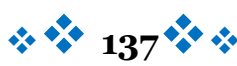


em conta a variedade de possibilidades de resultados em diferentes situações envolvendo chance. No pós-teste eles ampliaram suas previsões, baseando-se nos dados apresentados em cada contexto. Embora não tenham atingido um nível de conhecimento estatístico mais complexo, os estudantes apresentaram respostas mais adequadas após as intervenções. A diferença das respostas do pré para o pós-teste mostrou que alunos nessa faixa etária podem alcançar melhoras significativas quando estimulados utilizando variadas situações de amostragem.

Rubin, Bruce e Tenny, 1990; Garfield, 2003; Innabi, 2006 têm apontado em seus estudos dificuldades dos estudantes e de pessoas leigas em estatística em compreender conceitos básicos de amostragem. Além disso, não levam em conta, ao julgar a validade das amostras, fatores relevantes para representatividade da mesma como tamanho e variabilidade.

Percebendo-se a importância das habilidades relacionadas à Amostragem para o desenvolvimento do raciocínio estatístico, este estudo tem como objetivo identificar a compreensão de estudantes do $5^{\circ}$ e $9^{\circ}$ ano do Ensino Fundamental na elaboração e análise de critérios para escolha de uma amostra representativa.

\section{Método}

Participaram dessa pesquisa 40 estudantes, sendo 20 do $5^{\circ}$ ano (entre 9 e 10 anos) e 20 do $9^{\circ}$ ano (entre 13 e 14 anos) do Ensino Fundamental de 2 (duas) escolas da rede pública municipal de ensino da Região Metropolitana do Recife.

Foi elaborado o instrumento para coleta de dados, o qual continha 13 questões que abordavam diferentes aspectos relacionados à amostragem (GOMES, 2013). Contudo, neste artigo foi realizado um recorte da pesquisa e nos deteremos apenas às questões relacionadas diretamente a seleção, tamanho e representatividade de amostras, tendo como objetivo identificar a compreensão de estudantes em perceber e elencar critérios necessários para a seleção de uma amostra representativa.

Foram realizadas individualmente entrevistas semi-estruturadas nas quais os alunos foram questionados oralmente a partir de questões apresentadas impressas em cartões, os quais permitiam que os mesmos pudessem realizar a leitura quantas vezes desejassem. Como o que estava sendo avaliado não era a habilidade de leitura do estudante, em todas as atividades a pesquisadora também lia junto com o aluno a questão, buscando garantir que as questões apresentadas fossem compreendidas pelos estudantes.

Assim, buscou-se observar se os alunos compreendiam a importância de que a seleção de uma amostra não pode ser tendenciosa ou manipulada e que represente a população analisada. Para tal, foram realizadas duas questões. 
Questão 1: Um pesquisador queria saber a merenda preferida dos alunos das escolas públicas de Recife. Como ele não tinha condições de entrevistar todos os alunos resolveu entrevistar apenas 200 alunos. Como ele poderia escolher esses alunos para ter uma ideia melhor da preferência de todos?

Nessa primeira questão, o estudante foi estimulado a sugerir formas para seleção da amostra, sendo observados quais critérios foram estabelecidos pelo mesmo para a escolha dos sujeitos. Essa atividade visou perceber se o entrevistado compreendia que para a escolha da amostra é necessário estabelecer critérios que levem em conta os propósitos de cada pesquisa e busquem alcançar os objetivos da mesma.

Questão 2: Cinco amigos queriam saber aproximadamente quantos livros as pessoas que moram no bairro deles liam por ano. Como o bairro tinha uns 10.0oo moradores, não dava para entrevistar todo mundo. Cada um teve uma ideia para saber quem podiam entrevistar. Qual dessas ideias você acha que será melhor para saber o que eles querem? Por quê?

\begin{tabular}{|l|l|}
\hline Amigo 1 & 100 moradores que frequentavam a biblioteca da comunidade. \\
\hline Amigo 2 & 100 moradores do bairro. \\
\hline Amigo 3 & 10 moradores que frequentavam a biblioteca da comunidade. \\
\hline Amigo 4 & 10 moradores do bairro. \\
\hline Amigo 5 & Homens, mulheres, meninos e meninas. \\
\hline
\end{tabular}

A questão 2, foi adaptada de uma atividade realizada por Innabi (2006), abordava os conceitos de seleção, tamanho e representatividade da amostra. É importante destacar que as respostas dadas para esta questão foram utilizadas para analisar a criticidade dos estudantes em relação à seleção como um todo e se estes relacionam o tamanho da amostra como fator importante para a seleção da mesma. Foram apresentadas amostras de diferentes tamanhos e critérios de seleção, visando observar a capacidade de julgamento dos estudantes ao serem confrontados com diversas formas de seleção da amostra para uma mesma pesquisa.

Em relação ao tamanho, o estudante deveria levar em conta se o quantitativo apresentado para a amostra é considerado o ideal para o que a suposta pesquisa objetiva. Dessa forma, supõe-se que ele perceberia que o tamanho da amostra é um aspecto que deve ser levado em conta para a seleção da amostra.

Ao escolher qual amostra será mais representativa, o estudante também deverá observar a tendenciosidade na seleção da mesma. No caso desse exemplo, se o objetivo da pesquisa é saber a media de livros lidos por ano em um bairro X, entrevistar apenas 
frequentadores da biblioteca não garantiria que o resultado da pesquisa represente toda a população, pois a amostra teria um viés de seleção.

Estas questões também tinham como objetivo estimular o estudante a refletir sobre a importância da amostra ser variada, contendo características de toda a população para que seja representativa.

A partir das respostas dos alunos foram elaboradas, primeiramente, duas categorias (níveis) para as respostas apresentadas: adequadas $e$ inadequadas. Posteriormente, essas foram divididas em quatro subcategorias: não responde, responde incorretamente, responde parcialmente correto, responde corretamente. As quatro subcategorias foram elaboradas com o intuito de enriquecer a análise, observando e valorizando a diversidade das respostas apresentadas pelos estudantes.

\section{Resultados}

Na primeira questão, em relação à seleção de uma amostra, os estudantes foram convidados a propor uma estratégia para a seleção de uma amostra de forma que esta fosse o mais representativa possível da população analisada.

Questão o1 - Um pesquisador queria saber a merenda preferida dos alunos das escolas públicas de Recife. Como ele não tinha condições de entrevistar todos os alunos resolveu entrevistar apenas 200 alunos. Como ele poderia escolher esses alunos para ter uma ideia melhor da preferência de todos?

Para esta questão, o número de respostas adequadas é maior entre os participantes do $9^{\circ}$ ano (7 estudantes do $9^{\circ}$ ano e 5 estudantes do $5^{\circ}$ ano). Contudo, não houve diferença significativa entre os anos de escolaridade ( $\left.\mathrm{X}^{2} \mathrm{o}, 476, \mathrm{gl} 1, \mathrm{p}<0,490\right)$.

Na Tabela 1 estão apresentadas as frequências das respostas dos alunos em cada subcategoria por ano.

Tabela 1: Frequência por ano de escolaridade da pergunta 1.

\begin{tabular}{lcccc}
\hline Categorias & Ano de ensino & & & \\
& Não responde & o Ano & o Ano & otal \\
\hline Responde incorretamente & 1 & 2 & 3 \\
& & & & \\
Responde parcialmente correto & & & \\
Responde corretamente & & \\
\hline
\end{tabular}

Produção dos autores

Foram consideradas respostas incorretas aquelas que apresentaram características de amostras não-probabilísticas, ou seja, que não poderiam ser generalizadas para toda a 
população, pois não estabeleciam critérios para sua escolha ou ofereciam viés de seleção, como os exemplos a seguir:

Pesquisador - Como ele poderia escolher esses alunos para ter uma ideia melhor da preferência de todos?

Sujeito 6 - Pela professora.

Pesquisador - Como assim?

Sujeito 6 - É porque ele queria saber qual a merenda preferida.

Pesquisador - E como ele ia escolher esses alunos pela professora?

Sujeito 6 - Ele ia pegar a lista das professoras e elas iam escolher os alunos.

Pesquisador - E como ele ia escolher essas professoras?

Sujeito 6 - Na reunião ele ia perguntar quem queria.

Sujeito 11 - Perguntando de um em um.

Pesquisador - Perguntando de um por um? A todos os alunos?

Sujeito 11 - É.

Sujeito 23 - Pegar um aluno de cada escola. Sei lá!

Pesquisador - Ele ia pegar um aluno de cada escola do Recife?

Sujeito 23 - É.

Pesquisador - E como ele ia escolher esse aluno?

Sujeito 23 - Ia na sala e chamava. Do mesmo jeito que me chamou.

Pesquisador - Ia chamar ou perguntar quem queria?

Sujeito 23 - Era. Mais ou menos assim.

Foram consideradas como respostas corretas as que elencavam pelo menos um aspecto referente a uma amostra probabilística, ou seja, que pode ser generalizada para toda a população. Entre esse tipo de resposta foi comum os participantes sugerirem que a amostra fosse escolhida a partir de um sorteio, característica de uma amostra aleatória.

So2 - Sorteando.

$\mathrm{P}$ - Sorteando? Mas ia sortear o quê primeiro?

So2 - A merenda.

$\mathrm{P}$ - A merenda?

So2 - Não. Sortear os alunos.

$\mathrm{P}$ - Os alunos da onde?

So2 - Do colégio. Daqui

P - Então, pra ele saber qual a merenda preferida dos alunos de Jaboatão ele vai sortear os 200 alunos dessa escola?

So2 - Não. Tem que ser mais.

$\mathrm{P}$ - Ele ia escolher como as escolas?

So2 - Sorteando.

P - Sorteando também? Então ele iria sortear as escolas e das escolas sorteadas ele ia sortear os alunos?

So2 - (Concorda com a cabeça)

S28 - Ele dividia pelas escolas que tem no Recife e sorteava. 
Na segunda questão, ainda em relação à seleção de uma amostra, foi apresentada uma situação hipotética, na qual eram listadas cinco opções para a escolha da amostra, e os participantes eram solicitados a apontar qual seria a mais apropriada. No Gráfico 2, tem-se os resultados para essa questão.

Questão o2 - Cinco amigos queriam saber aproximadamente quantos livros as pessoas que moram no bairro deles liam por ano. Como o bairro tinha uns 10.000 moradores, não dava para entrevistar todo mundo. Cada um teve uma ideia para saber quem podiam entrevistar. Qual dessas ideias você acha que será melhor para saber o que eles querem? Por quê?

\begin{tabular}{|l|l|}
\hline Amigo 1 & 100 moradores que frequentavam a biblioteca da comunidade. \\
\hline Amigo 2 & 100 moradores do bairro. \\
\hline Amigo 3 & 10 moradores que frequentavam a biblioteca da comunidade. \\
\hline Amigo 4 & 10 moradores do bairro. \\
\hline Amigo 5 & Homens, mulheres, meninos e meninas. \\
\hline
\end{tabular}

Mais uma vez não houve diferença estatística entre os anos de escolaridade analisados $\left(\mathrm{X}^{2}\right.$ 1,290, gl 1, p < 0,256). Dos 20 estudantes de cada ano, apenas 3 participantes do $5^{\circ}$ ano e 6 do $9^{\circ}$ ano responderam de forma adequada. Os resultados desta questão, semelhantemente a atividade anterior, confirmam a dificuldade dos estudantes em selecionar uma amostra mais representativa possível.

Para uma melhor análise dessas dificuldades e das respostas apresentadas pelos estudantes, a Tabela 2 traz a classificação das respostas nas quatro subcategorias.

Tabela 2: Frequência por ano de escolaridade da pergunta 2.

\begin{tabular}{lcccc}
\hline & Ano de ensino & & & \\
Categorias & o Ano & o Ano & otal \\
\hline $\begin{array}{l}\text { Não responde } \\
\text { Responde incorretamente }\end{array}$ & 6 & 4 & 0 \\
Responde parcialmente correto & & & \\
Responde corretamente & & & \\
\hline
\end{tabular}

Produção dos autores

Nessa variável, estava sendo observado se os participantes seriam tendenciosos na escolha da amostra. 
A opção mais adequada seria o Amigo 2, que entrevistou 100 moradores do bairro independente de ir à biblioteca ou não, o que deixa implícito que na amostra existiriam frequentadores e não-frequentadores da biblioteca, que poderiam ser de diferentes gêneros e faixas etárias.

Os estudantes que escolheram o Amigo 5 (homens, mulheres, meninos e meninas), tiveram suas respostas classificadas como parcialmente corretas, pois argumentaram sobre a variabilidade de gênero e idade. Entretanto, não consideraram importante o fato da amostra ser dos moradores do bairro.

Na Tabela 2 nota-se que, mais da metade dos estudantes (dezesseis do $5^{\mathrm{o}}$ ano e quatorze do $9^{\circ}$ ) responderam incorretamente, apresentando um viés de seleção em suas opções, como nos exemplos abaixo:

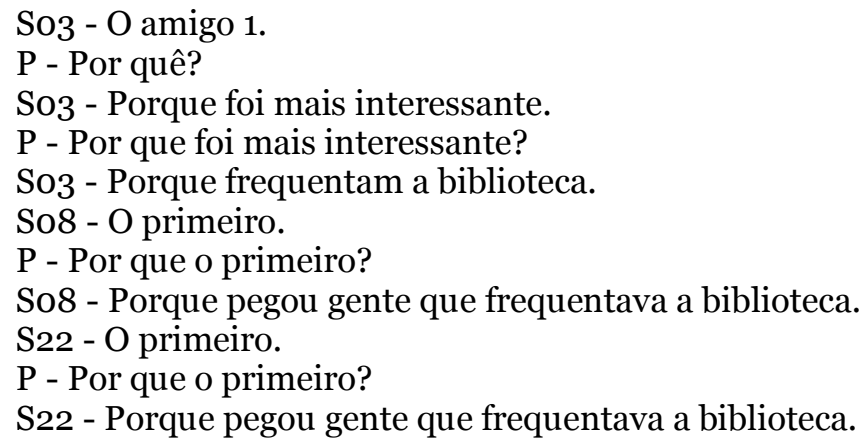

Percebe-se que, esses estudantes quando solicitados a justificar a sua escolha argumentavam por ser uma amostra que frequentava a biblioteca, característica que torna a amostra tendenciosa e, portanto, não generalizável para toda a população.

As respostas consideradas parcialmente corretas (duas do $5^{\circ}$ ano e cinco do $9^{\circ}$ ano) foram classificadas de tal forma, pois, embora optassem por uma amostra não tendenciosa, suas justificativas não abordavam o porquê de uma amostra do bairro todo ser melhor que apenas a dos frequentadores da biblioteca.

S25 - O 2 que entrevistou 100 [...]

$\mathrm{P}$ - Mas o um também entrevistou 100. Por que o 2 e não o 1 ?

S25 - Porque é do bairro todo e o outro foi da biblioteca.

Apenas dois estudantes deram uma resposta levando em conta que entre a amostra de moradores do bairro haveria pessoas que frequentavam ou não a biblioteca, permitindo com que esta representasse de forma mais significativa a população da pesquisa.

S13 - Pegou quem vai e quem não vai (para a biblioteca).

S40 - Porque era do bairro mesmo sem ir "pra" biblioteca.

ISSN 2526-2882 
A análise seguinte refere-se à mesma questão, mas analisamos as respostas em função do tamanho da amostra, o qual deve ser definido claramente para a seleção da mesma. A situação apresentada aos participantes para essa observação foi a mesma para a segunda análise sobre seleção da amostra, mas avaliando se os estudantes levavam em conta o tamanho da amostra escolhida em relação ao tamanho da população.

Ao contrário da maioria das questões, essa apresentou um maior quantitativo de respostas adequadas ( 15 do $9^{\circ}$ ano e 9 do $5^{\circ}$ ). Embora haja diferença entre os anos de escolaridade a mesma não foi significativa $\left(\mathrm{X}^{2} 3,75 \mathrm{o}, \mathrm{gl} 3, \mathrm{p}<0,053\right)$.

Ao subdividir as respostas, percebe-se que o maior quantitativo de participantes responde parcialmente correto ou não responde, ou seja, não relaciona o tamanho da amostra com a população ou estabelece uma relação sem justificativas claras.

Tabela 3: Frequência por ano de escolaridade da pergunta 2 em relação ao tamanho da amostra.

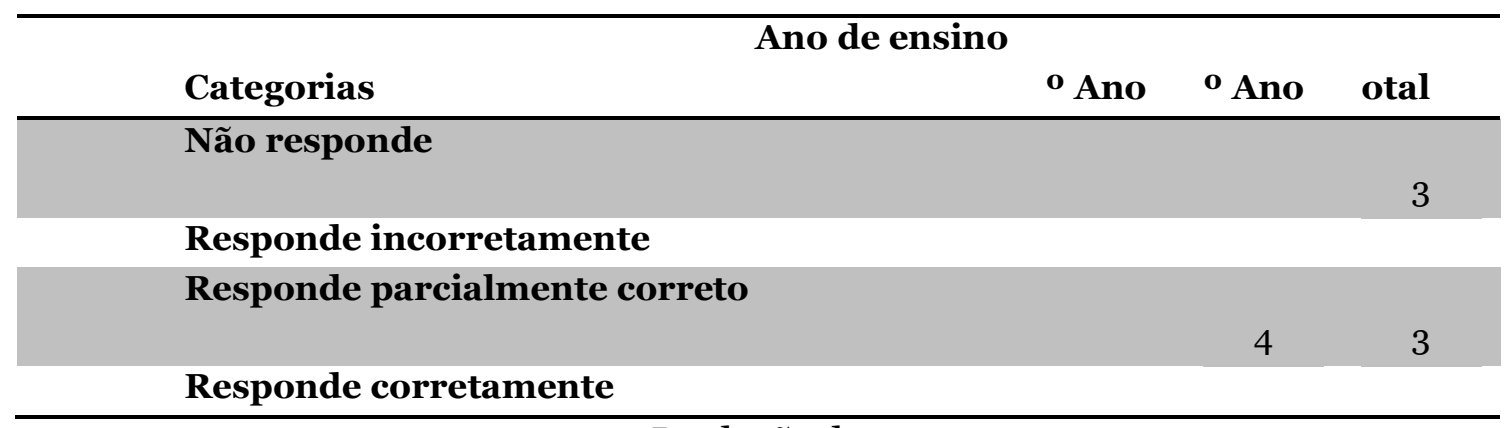

Produção das autoras

Nesta variável é interessante perceber que, quando os participantes escolheram a amostra que consideravam ideal, os mesmos eram questionados sobre outra opção semelhante ou no quantitativo de pessoas ou no local de pesquisa. Por exemplo, se o estudante optasse pelo Amigo 1 justificando por ser 100 moradores, ele era conflitado com o Amigo 2, que também era uma amostra de 100 pessoas. Caso este argumentasse por serem frequentadores da biblioteca era indagado por que não o Amigo 3, que também tinha uma amostra de pessoas que iam à biblioteca. Essas comparações foram feitas com qualquer resposta dada. Contudo ainda não foi suficiente para que os participantes relacionassem o tamanho da amostra com a população pesquisada.

Poucos estudantes relacionaram incorretamente (dois do $5^{\circ}$ ano e um do $9^{\circ}$ ), argumentando que cem pessoas era muito ou sem estabelecer ligação entre o número de moradores do bairro e a necessidade da amostra ser representativa deste.

So5 - Porque é melhor tia. O primeiro pegou 100 pessoas. Assim, eu acho que é o 4 porque não tem muitas pessoas.

S39 - Mas é muita gente, pode dar alguma coisa e não dar certo. 
As respostas consideradas como parcialmente corretas tiveram essa classificação, pois os estudantes apenas levaram em conta a maior quantidade de moradores, sem relacionar a população com o número de sujeitos da amostra e um dos critérios para a sua representatividade.

So1 - Porque o um tem mais moradores.

$\mathrm{S} 13-[\ldots] \mathrm{O}$ 2. Porque tem mais pessoas.

S33 - Porque tem mais ideia, tem mais gente.

Os dados da Tabela 3 mostram que somente um participante do $9^{\circ}$ ano respondeu corretamente, destacando que o tamanho da amostra é um dos fatores importantes para representatividade desta. E que, embora uma amostra menor também pudesse representar a população no exemplo citado, seria mais adequado um número maior de sujeitos.

S34 - [...] porque o três pegou só 10. Vai dar, mas vai dar muito pouco pra saber do bairro todo.

Nos estudos de Rubin, Bruce, e Tenny (1990) com estudantes do Ensino Médio, os participantes demonstraram modelos inconsistentes em relação à seleção da amostra para que esta represente a população desejada, pois ao analisarem os resultados obtidos perceberam que, as respostas dos estudantes ora são embasadas em suas intuições sobre representatividade da amostra, ora na variabilidade da mesma, não sendo o tamanho da amostra relacionado a esses conceitos.

Essa compreensão acerca da validade da amostra também foi analisada por Innabi (2006) de forma semelhante ao realizado em nossa pesquisa. Ao serem questionados sobre a validade de uma amostra, apresentando-se maneiras diferentes de como esta poderia ter sido selecionada, a maioria dos estudantes do ensino secundário não levou em consideração ao justificarem suas respostas, o tamanho da amostra e nem se a mesma é tendenciosa ou não quando julgaram a validade e representatividade da mesma.

Nos estudos de Watson e Kelly (2002), estudantes entre 8 e 9 anos levantaram questões sobre a seleção de uma amostra representativa para o todo, entretanto, apresentaram dificuldade em compreender ideias acerca do tamanho da amostra.

O mesmo pode ser percebido ao analisarmos os resultados apresentados aqui, a maioria dos entrevistados não conseguiu elencar aspectos importantes que devem ser levados em consideração ao selecionar uma amostra, tais como variabilidade, tamanho e tendenciosidade da mesma, demonstrando a necessidade de se trabalhar com situações de pesquisa, nas quais os estudantes possam vivenciar as etapas de uma pesquisa estatística 
desenvolver habilidades para a seleção de uma amostra representativa. Embora em relação ao tamanho da amostra o desempenho dos participantes desta pesquisa tenha sido mais adequado, a maioria das suas respostas apenas levava em conta a amostra maior, sem relacionar a população com o número de sujeitos da amostra e a importância deste para a sua representatividade.

O nosso estudo, bem como pesquisas anteriores, apontou que a elaboração de critérios para a seleção de uma amostra a fim de que esta seja a mais representativa possível é uma tarefa difícil para estudantes de diferentes idades. A partir dos resultados alcançados no que diz respeito ao tamanho da amostra avaliamos se este pode ser um aspecto utilizado como ponto de partida para explanar o cuidado necessário para seleção de amostras. Propor atividades que envolvam os conhecimentos que os estudantes já possuem sobre amostragem ou relacionados pode ser uma alternativa para desenvolver outros conceitos mais complexos.

O trabalho com diferentes atividades contribui para a construção desses conceitos, como observado nos estudos de Pfannkuch (2008) a qual desenvolveu uma sequência didática acerca dos conceitos referentes à amostra com tamanhos diferentes e indicou que os alunos passaram a compreender algumas noções sobre variabilidade da amostragem, ligando a amostra à população, utilizando a linguagem associada à Estatística ou embasando suas respostas a partir das imagens e dados fornecidos.

Embora alguns resultados sejam semelhantes a estudos anteriores, vale destacar que, o enfatizado nessa pesquisa é a necessidade da junção de dois fatores: atividades que envolvam vários elementos e conceitos ligados a amostragem, que partam do contexto e interesse dos alunos, bem como o início deste trabalho desde os anos iniciais do Ensino Fundamental.

\section{Conclusões}

A partir da análise dos dados encontrados, percebeu-se que estabelecer critérios para a seleção de uma amostra representativa, que possa refletir as características da população de interesse, é uma tarefa complicada para estudantes de diferentes idades. No entanto, propor atividades nas quais os alunos possam aplicar seus conhecimentos sobre amostragem mostrou-se uma alternativa para desenvolver conceitos e resolver situaçõesproblema mais complexos.

Os resultados alcançados aqui confirmaram outras pesquisas realizadas com estudantes mais velhos (Gil e Ben-Zvi, 2010; Rubin, Bruce e Tenny, 1990; Garfield, 2003; Innabi, 2006) que elencaram dificuldades dos estudantes em perceber a implicações da representatividade da amostra e relacioná-la a outros fatores como tamanho e variabilidade.

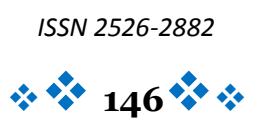


Entretanto, acreditamos que as respostas mais adequadas dão indícios de que, se instigados, estudantes de diferentes idades são capazes de desenvolver habilidades necessárias para elencar critérios necessários para a validade de uma amostra, visto que estudantes do $5^{\mathrm{o}}$ ano apresentaram justificativas parcialmente corretas ou corretas, nas quais estava implícita a relevância da variabilidade da amostra. Isso demonstra que, embora os alunos não tenham conseguido elaborar uma resposta mais formal e completa, eles percebem que para que uma amostra seja válida ela deve ter algumas características específicas da população.

Nesse sentido, percebe-se que este estudo nos mostra a possibilidade e capacidade de trabalhar conceitos relacionados a amostragem com estudantes desde os anos iniciais, favorecendo a compreensão destes e também de conteúdos mais complexos abordados durante a vida escolar do sujeito.

Assim, ressaltamos a necessidade da elaboração de estratégias sistemáticas de ensino que corroborem para a superação de tais dificuldades, envolvendo diferentes situações que abordem os conceitos vinculados à Amostragem, a fim de proporcionar uma aprendizagem mais significativa e novas possibilidades para o ensino de Estatística.

\section{Referências}

BEN-ZVI, D., MAKAR, K., BAKKER, A. \& ARIDOR, K. Children's emergent inferential reasoning about samples in an inquiry-based environment. In: Seventh Congress of the European Society for Research in Mathematics Education, Rzeszów, Poland, 9 - 13 February, 2011.

BUSSAB, W. O. e MORETTIN, P. A. Estatística básica. 5. ed. São Paulo: Saraiva, 2002.

DANCEY, C. P. e REIDY, J. Estatística sem Matemática para Psicologia: Usando SPSS para Windows. 3. ed. Porto Alegre: Artmed, 2006.

ESTEVAM, E. J. G. e FÜRKOTTER, M. A variabilidade como fator (res)signicante para a Educação Estatística no Ensino Fundamental. Anais do X Encontro Nacional de Educação Matemática. Salvador, 2010.

GAL, I. Adult's Statistical Literacy: meanings, components, responsibilities. International Statistical Review, v. 70, n. 1, p. 1-25, 2002.

GARFIELD, J. Assessing Statistical Reasoning. Statistics Education Research Journal.

v.2. n. 1. p. 22-38, 2003. Disponível em: <http://www.stat.auckland.ac.nz/ $\sim$ iase/serj/SERJ2(1).pdf $>$. Acesso em: 12 set. 2010.

GOMES, T. M da S. O todo é a soma das partes, mas uma parte representa o todo? : compreensão de estudantes do $5^{\circ}$ e $9^{\circ}$ ano sobre amostragem. Dissertação de Mestrado, Universidade Federal de Pernambuco, 2013. 109 F.

ISSN 2526-2882 
GUIMARÃES, G.; GITIRANA, V. Estatística no ensino fundamental: a pesquisa como eixo estruturador. In: BORBA e MONTEIRO (Org). Processos de Ensino e Aprendizagem em Educação Matemática. Editora UFPE, Recife, 2013. p. 93-132.

INNABI, H. Factors considered by secondary students when judging the validity of a given statistical generalization. Proceedings of the Seventh International Conference on Teachings Statistics, Brasil, 2006. Disponível em: <http://www.stat. auckland.ac.nz/ iase/publications/17/2B1_INNA.pdf >. Acesso em: 6 set. 2010.

PFANNKUCH, M. Building sampling concepts for statistical inference: A case study. In: Eleventh International Congress on Mathematics Education, Monterrey, Mexico, 6 - 13 July, 2008.

RUBIN, A. D., BRUCE, B. C. and TENNEY, Y. Learning About Sampling: Trouble at the Core of Statistics. Proceedings of the Third International Conference on Teachings Statistics. p. 314-319, New Zeland, 1990. Disponível em: <http://www.stat.auckland.ac.nz/ iase/publications/18/BOOK1/A9-4.pdf>. Acesso em: 7 set. 2010.

WATSON, J.M. and KELLY, B. A. Can grade 3 students learn about variation? Proceedings of the Sixth international Conference on Teachings Statistics, South Africa, 2002.

\section{Biografia Resumida}

Gilda Lisbôa Guimarães - Pedagoga pela PUC/SP; Mestre e Doutora em Psicologia Cognitiva pela UFPE; Pós-doutorado na Universidad de Burgos- Espanha e na Université Laval- Quebec. Professora Adjunta da Universidade Federal de Pernambuco, docente do Departamento de Métodos e Técnicas de Ensino e da Pós-graduação em Educação Matemática e Tecnológica. Líder do grupo de pesquisa GREF (Grupo de Estudo em Educação Estatística no Ensino Fundamental).

Link do lattes: http://lattes.cnpq.br/2681053695821897

e-mail:gilda.lguimaraes@gmail.com

Tâmara Marques da Silva Gomes - Pedagoga pela UFPE; Especialista em Coordenação e Supervisão Pedagógica; Mestre ISSN 2526-2882

$$
* 148 *
$$


em Mestre em Educação Matemática e Tecnológica pela UFPE e Doutoranda em Educação Matemática e Tecnológica pela UFPE. Atua como supervisora escolar na Rede Municipal de Jaboatão dos Guararapes e no Ensino Superior de rede privada. É membro do grupo de pesquisa GREF (Grupo de Estudo em Educação Estatística no Ensino Fundamental).

Link do lattes: http://lattes.cnpq.br/6453076429453666

e-mail: tamaramarquesgomes@gmail.com 